\title{
Comparison of DNA Methylation in Schwann Cells before and after Peripheral Nerve Injury in Rats
}

\author{
Xian-Hu Zhou, ${ }^{1,2}$ Wei Lin, ${ }^{1,2}$ Yi-Ming Ren, ${ }^{1,2}$ Shen Liu, ${ }^{1,2}$ Bao-You Fan, ${ }^{1,2}$ Zhi-Jian Wei, \\ Gui-Dong Shi, ${ }^{1,2}$ Xin Cheng, ${ }^{1,2}$ Yan Hao, ${ }^{1,2}$ and Shi-Qing Feng ${ }^{1,2}$ \\ ${ }^{1}$ Department of Orthopedics, Tianjin Medical University General Hospital, Tianjin, China \\ ${ }^{2}$ Tianjin Neurological Institute, Key Laboratory of Post-Neuroinjury Neuro-Repair and Regeneration in Central Nervous System, \\ Ministry of Education and Tianjin City, Tianjin, China \\ Correspondence should be addressed to Shi-Qing Feng; sqfeng@tmu.edu.cn
}

Received 2 December 2016; Revised 23 February 2017; Accepted 8 March 2017; Published 26 March 2017

Academic Editor: Simone Di Giovanni

Copyright (C) 2017 Xian-Hu Zhou et al. This is an open access article distributed under the Creative Commons Attribution License, which permits unrestricted use, distribution, and reproduction in any medium, provided the original work is properly cited.

\begin{abstract}
This study aims to find the difference of genomewide DNA methylation in Schwann cells (SCs) before and after peripheral nerve system (PNS) injury by Methylated DNA Immunoprecipitation Sequencing (MeDIP-Seq) and seek meaningful differentially methylated genes related to repairment of injured PNS. SCs harvested from sciatic nerve were named as activated Schwann cells (ASCs), and the ones harvested from brachial plexus were named as normal Schwann cells (NSCs). Genomic DNA of ASCs and NSCs were isolated and MeDIP-Seq was conducted. Differentially methylated genes and regions were discovered and analyzed by bioinformatic methods. MeDIP-Seq analysis showed methylation differences were identified between ASCs and NSCs. The distribution of differentially methylated regions (DMRs) peaks in different components of genome was mainly located in distal intergenic regions. GO and KEGG analysis of these methylated genes were also conducted. The expression patterns of hypermethylated genes (Dgcr8, Zeb2, Dixdc1, Sox2, and Shh) and hypomethylated genes (Gpr126, Birc2) detected by qRT-PCR were opposite to the MeDIP analysis data with significance $(p<0.05)$, which proved MeDIP analysis data were real and believable. Our data serve as a basis for understanding the injury-induced epigenetic changes in SCs and the foundation for further studies on repair of PNS injury.
\end{abstract}

\section{Introduction}

Schwann cells (SCs) play an important role in the peripheral nervous system (PNS) and have been shown to have a variety of functions especially in participating in the formation of myelin, maintaining the morphology and function of myelin sheath as well as involving in the regeneration of nerve injury [1-4]. Particularly when PNS was injured, biological functions of SCs changed significantly and cannot be replaced. In response to nerve injury, a series of complex changes will occur at the distal end of the nerve, and this change process is called Wallerian degeneration [5]. With axonal degeneration, SCs are activated and proliferating rapidly, which helps to clear myelin and axon debris, guide axonal regrowth, and provide neurotrophic support [6-9]. Besides,
SCs dedifferentiate into repair cells that are essential for axonal regeneration and then differentiate into myelinating SCs to restore nerve function [10].

Recently, a large number of studies have been focusing on epigenetics research of SCs related to PNS injury, and some studies [11-14] have showed that microRNAs and histone deacetylases of SCs emphasized the importance of epigenetic mechanisms for peripheral myelination after PNS injury. What is more, some studies [10] have reported that myelination of SCs can be regulated by DNA methylation process. Although previous studies $[15,16]$ have provided some clues for understanding the relationship between DNA methylation and gene regulation of SCs, due to the limitation of experimental technique, the mechanisms driving all of this still are not understood very well. In this study, for the 
first time, we comprehensively characterized the differences of genomewide DNA methylation expression regarding SCs before and after PNS injury by Methylated DNA Immunoprecipitation Sequencing (MeDIP-Seq). This research aims to seek meaningful differentially methylated genes, allowing deeper insight into molecule mechanisms of SCs during PNS injury process.

\section{Methods and Materials}

2.1. Animals and Surgery. Adult Wistar rats $(n=6$, $180-200 \mathrm{~g}$ ) were obtained from the Animal Center of Tianjin Medical University. Sciatic nerve injury surgeries were done as described previously [17]. Rats were anesthetized by intraperitoneal injection of ketamine $(75 \mathrm{mg} / \mathrm{kg})$. Under aseptic conditions, muscles and skins were carefully sutured. Bilateral sciatic nerves were exposed and ligated with silk thread on the proximal end of the sciatic nerve. All the experimental procedures involving animals were conducted according to Institutional Animal Care guidelines of Tianjin Medical University, China, and approved ethically by the Ethics Committee of Tianjin Medical University, China.

2.2. Schwann Cells Isolation and Culture. After 7 days, sciatic nerves and brachial plexus were acquired from 6 Wistar rats. After washing away the blood in phosphate-buffered saline (PBS) and removing the epineurium and connective tissue under the dissecting microscope, the tissues were cut into $1 \times 1 \mathrm{~mm}$ explants with scissors [18]. SCs harvested from sciatic nerve were named as activated Schwann cells (ASCs), and the ones harvested from brachial plexus were named as normal Schwann cells (NSCs). Respectively, these tissues were digested in $5 \mathrm{mg} / \mathrm{mL}$ type I collagenase at $37^{\circ} \mathrm{C}$ for $7 \mathrm{~min}$ and in $0.25 \%$ trypsin (Sigma \# T4549) for $5 \mathrm{~min}$. The density of SCs was adjusted to $1 \times 10^{5} / \mathrm{mL}$. SCs were cultured in Dulbecco's modified Eagle's medium (DMEM) with $50 \mathrm{ug} / \mathrm{mL}$ penicillin-streptomycin on polylysine-coated dishes at $37^{\circ} \mathrm{C}$ and $5 \% \mathrm{CO}_{2}$. When SCs covered $85 \%$ of bottom of flask, the passage cells were digested with $0.25 \%$ trypsin $\left(37^{\circ} \mathrm{C}, 5 \mathrm{~min}\right)$.

2.3. Immunohistochemistry. The purified SCs were cultured to the third generation and were planted on poly-D-lysinecoated coverslips in 24-well plates. After 72 hours, SCs were briefly washed with PBS and fixed with $4 \%$ paraformaldehyde for 15 minutes. Then these cells were washed 3 times with PBS and permeabilized with $0.5 \%$ Triton X-100 15 min. After blocking with $0.5 \%(\mathrm{v} / \mathrm{v})$ goat serum in $\mathrm{PBS}$ for 1 hour at room temperature, these cells were incubated with S100ß antibody (mouse anti-rat antibody, 1:500 volume dilution) overnight at $4^{\circ} \mathrm{C}$. After washing 3 times in PBS, SCs were incubated with conjugated secondary antibodies (FITC) goat anti-mouse IgG for 1 hour (diluted 1:1000 in PBS). Lastly, the nuclei were stained with DAPI and images were captured using a laser scanning confocal microscope.

2.4. Cell Proliferation Assay. Cell Counting Kit-8 (CCK8, Dojindo, Japan) was used in cell proliferation assays.

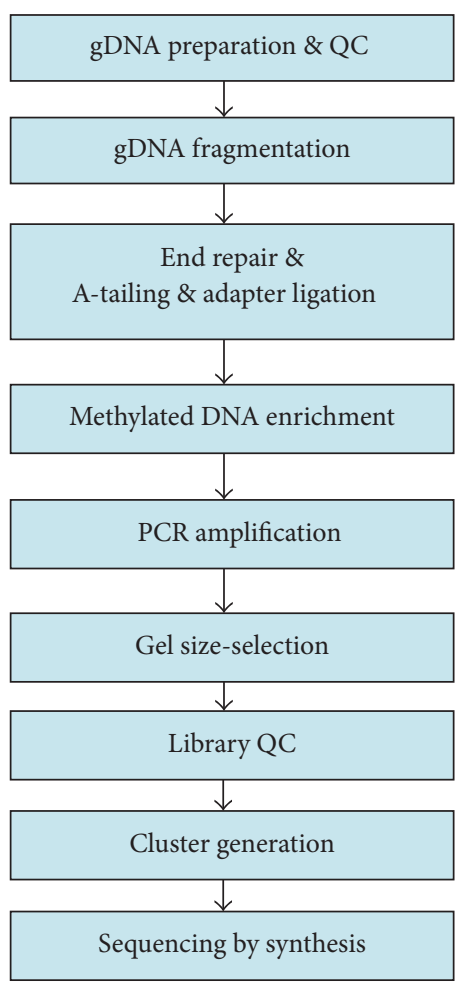

FIGURE 1: Concise experimental procedure for DNA methylation sequencing.

These cells were seeded into 96-well plates, and 3 duplicate wells were set. At the same time 3 control wells were set correspondingly. The density of cells was 1000 per well with $100 \mathrm{uL}$ growth medium. Then cells were treated with the CCK8 (10 uL, 2 hours per well) and measuring the numbers of cells per well was conducted by the absorbance $(450 \mathrm{~nm})$ of reduced water-soluble tetrazolium salt (WST) for 7 days continuously.

2.5. High-Throughput MeDIP Sequencing Analysis. The genomic DNA of ASCs and NSCs was extracted and purified, respectively. Then sonication method was used to fragment these DNA into 100-500 bp fragments. DNA fragment $3^{\prime}$ end repair was carried out by adding Adenine (A) and sequencing adapters were simultaneously added to their ends by PairedEnd DNA Sample Prep Kit (Illumina, USA). Double stranded DNA was denatured as single stranded DNA. Subsequently, sequencing adapters-ligated DNA fragments and 5-methylcytosine (5-mC) antibody beads (Diagenode, USA) were immunoprecipitated. These methylated DNA fragments were enriched. Then immunoprecipitated products were amplified and validated by quantitative realtime polymerase chain reaction (qRT-PCR), and those of 200-300 bp were excised from the gel and purified. DNA library quality control and sequencing run were processed by Illumina HiSeq 2000 platform (Illumina, USA). Finally, we got the Illumina sequencing raw data of DNA. Concise experimental procedure for DNA methylation sequencing was shown in Figure 1. 
2.6. Data Analysis. Data analysis was carried out according to the following steps. First, the previous sequencing data of DNA was used and the high quality data of them were screened out according to the screening criteria as follows: (1) Nitrogenous (N) base content of each read is not more than 5\%; (2) low quality base is not more than $30 \%$; (3) read does not contain an adapter sequence. Second, the high quality read was mapped to the latest rat genome assembly (http://hgdownload.soe.ucsc.edu/goldenPath/rn5/bigZips/). Read distribution analysis containing the distribution in rat chromosomes and differentially methylated regions (DMRs) (such as promoter $(\leq 1 \mathrm{~kb})$, promoter $(1-2 \mathrm{~kb})$, 1 st exon, other exons, 1st intron, other introns, $3^{\prime}$ UTR, $5^{\prime}$ UTR, distal intergenic regions, and downstream $(\leq 3 \mathrm{~kb})$ and $\mathrm{CpG}$ islands (CGIs)) was discovered from uniquely mapped reads. CpG islands were downloaded from UCSC database. Third, differentially methylated genes were screened according to $p<0.05$ and $\log 2$ (ASCs/NSCs) $>0$ or $\log 2$ (ASCs/NSCs) < 0 . Last, by using the Model-based Analysis of ChIPSeq (MACS) V 1.4.2 (http://liulab.dfci .harvard.edu/MACS/), the genomewide methylation peak scanning was performed and we analyzed the number of peaks in different components of the rat genome. Besides, the number of methylated peaks in the whole genome known as the total peak number and a peak overlapping different components were also analyzed. Gene ontology (GO) enrichment analysis and Kyoto Encyclopedia of Genes and Genomes (KEGG) pathway analysis were performed using DAVID6.7 database (http://david.abcc.ncifcrf.gov/).

2.7. $q R T-P C R$ Verification. Seven genes were verified by qRT-PCR with the Bio-Rad CFX96 Real-Time PCR System (Bio-Rad, USA). Total RNA was isolated from the ASCs and NSCs by using TRIZOL (Invitrogen Corp, Carlsbad, CA) and was polyadenylated and reverse-transcribed with a poly(T) adapter into cDNA following the manufacturer's directions. Real-time PCR was performed using SYBR green dye in a thermal cycler with the following parameters: an initial denaturation step at $95^{\circ} \mathrm{C}$ for $30 \mathrm{~min}$; 40 cycles at $95^{\circ} \mathrm{C}$ for 5 seconds and $60^{\circ} \mathrm{C}$ for 30 seconds. Complete experimental process was performed for each sample in triplicate. All primers were synthesized by Shanghai Shenggong Inc, and mRNA-specific primers were listed in Table S2, in Supplementary Material available online at https://doi.org/10.1155/2017/5393268. All data were analyzed using the $2^{-\triangle \Delta \mathrm{CT}}$ method to calculate the difference between the threshold cycle (CT) values of the target genes in each sample.

2.8. Statistical Analysis. All data were analyzed using SPSS statistical software (version 11.5 for Windows). Statistical analysis was performed using two-tailed Student's $t$-test, and differences were considered statistically significant at $p<$ 0.05 .

\section{Results}

3.1. Identification of Schwann Cells. The results of observation under optical microscope showed no morphological differences between ASCs and NSCs (Figures 2(a) and 2(b)). SCs, long spindle cells, all were arranged in fish shape and nucleus was ovoid or oblong. Both of two kinds of SCs had positive results under fluorescence microscope after S100ß immunocytochemistry staining (Figures 2(c)-2(e)). In the same culture condition, ASCs were faster to attach the wall than NSCs, and division rate and growth rate of ASCs were higher than those of NSCs (Figure 2(f)).

3.2. Methylomic Profiling of ASCs and NSCs. After MeDIPSeq, we generated a total of $6,592,337,700 \mathrm{bp}$ data from ASCs groups and 7,136,742,100 bp data from NSCs groups. 17474976 reads were obtained in NSCs groups and 16816796 reads in ASCs groups were obtained, respectively. To our satisfaction, 16415908 reads of NSCs group and 15729752 reads of ASCs group were uniquely mapped to the latest rat genome, which showed that more than $93 \%$ of MeDIPSeq reads were aligned (mapped) on latest rat genome in each group. In addition, more than $80 \%$ of MeDIP-Seq reads were high quality (HQ) mapped reads in Table 1. Besides, sequencing statistics revealed that all six samples performed well, with anticipated GC content skewedness of all mapped reads (Supplementary Material 1: Table S1).

3.3. Characterization of Differential Methylated Regions. A total of $13005381 \mathrm{HQ}$ mapped reads in ASCs group and 13137926 HQ mapped reads in NSCs group were distributed in the chromosomes of the DMRs. Of them, HQ mapped reads mainly were found in chrl and detailed results were showed in Table 2. There are 11610434 genome regions in total and 176,610 DMRs were identified. Among DMRs, 44.1\% were hypermethylated and 55.9\% were hypomethylated in Table 3. The DMRs were all located in promoter $(\leq 1 \mathrm{~kb})$, promoter (1-2 kb), 1st exon, other exons, 1st intron, other introns, $3^{\prime}$ UTR, 5' UTR, distal intergenic regions, downstream regions $(\leq 3 \mathrm{~kb})$, and CGls in Figure $3(\mathrm{a})$. The distribution of DMRs peaks in different components of genome showed that uniquely mapped reads in distal intergenic regions had a relatively higher methylation level than others $(65.10 \%$ in NSCs group, 66.43\% in ASCs group) in Figures 3(b) and 3(c). Only 567 DMRs peaks in CGls account for only 0.32 percent. Assessing the enrichment of methylated regions revealed that the relative frequency of $\mathrm{CpGs}$ within the regions and the observed/expected ratio of CpGs within the regions were above 1 in all cases between three ASCs groups and three NSCs groups, indicating a successful enrichment of methylated fragments in the data sets (Table 4).

3.4. Hypermethylated or Hypomethylated Genes. A total of 176612 methylated genes between ASCs and NSCs were detected by high-throughput MeDIP sequencing analysis $(p<0.05)$. Among them, 77800 genes were hypermethylated and 98812 genes were hypomethylated. According to screening criteria, fold change and whether CGls of these genes are 


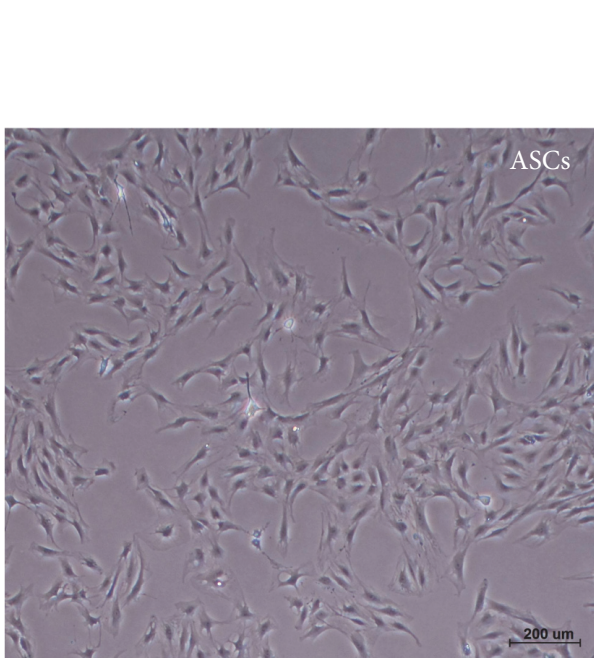

(a)

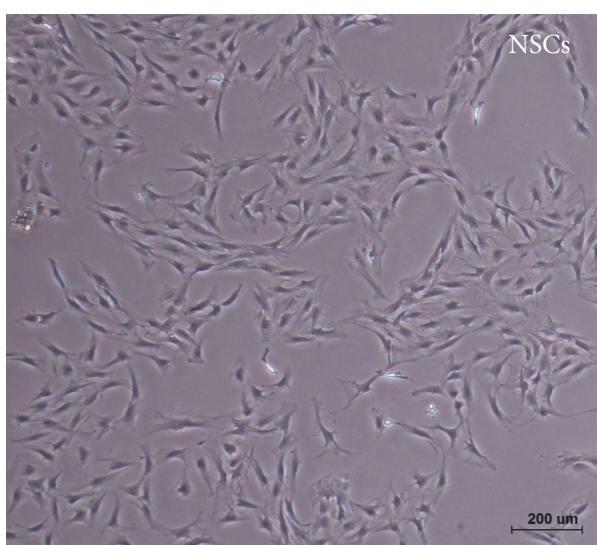

(b)
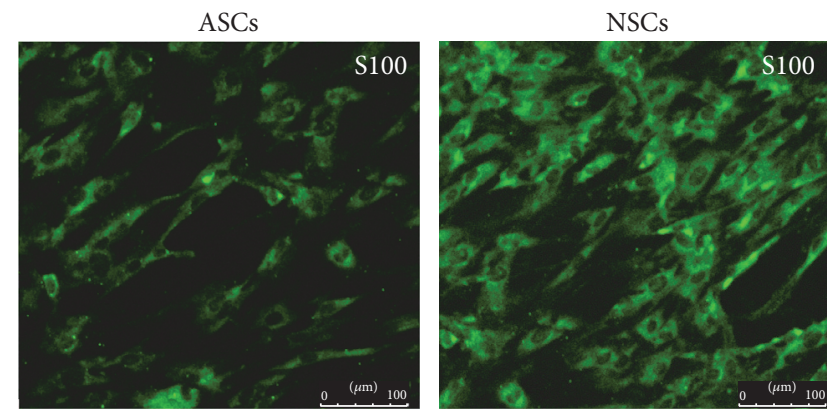

(c)
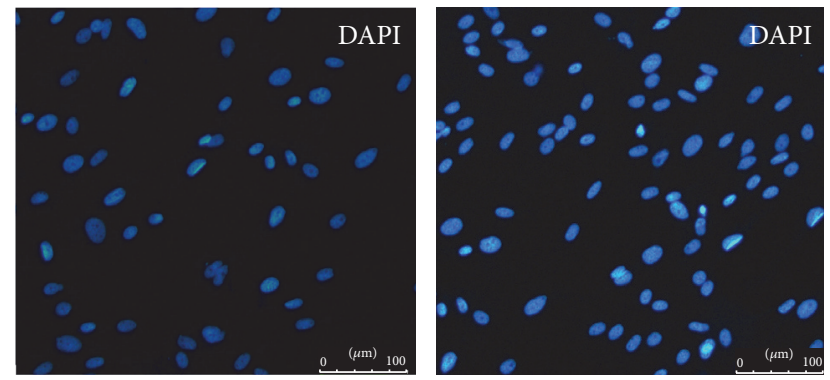

(d)
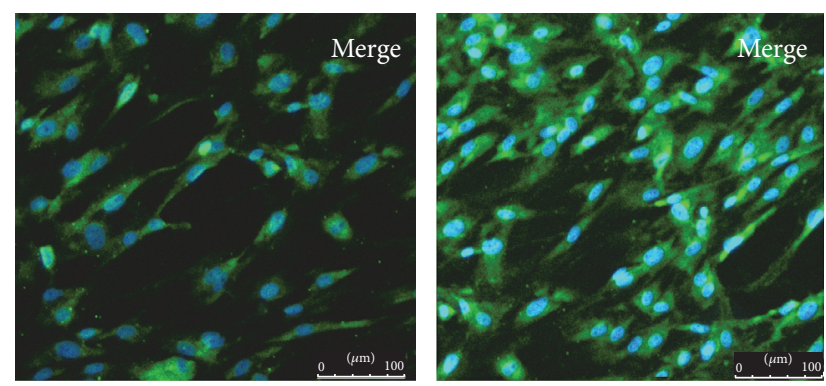

(e)

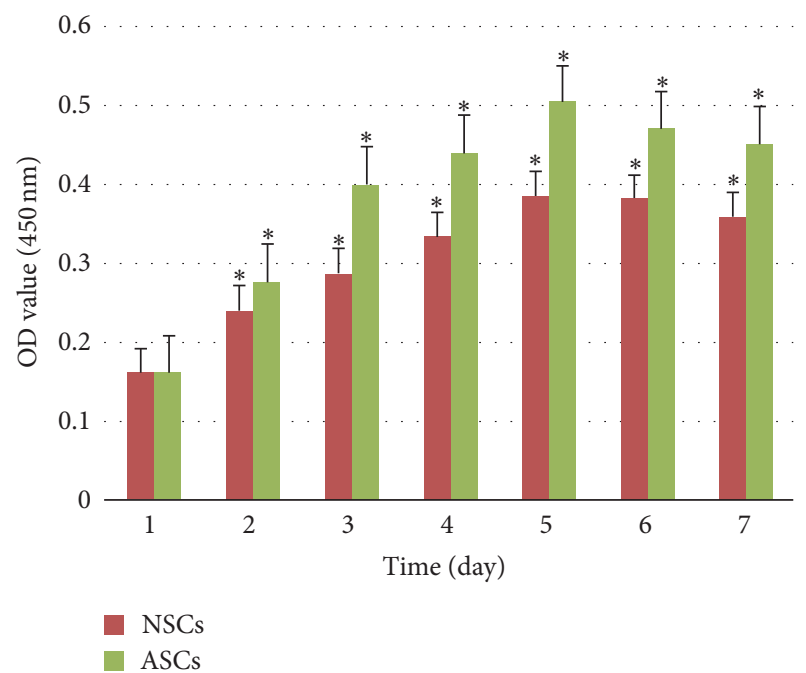

(f)

FIGURE 2: (a) The shape of activated Schwann cells (ASCs) under optical microscope. (b) The shape of normal Schwann cells (NSCs) under optical microscope. Both of these SCs, long spindle cells, were arranged in fish shape and nucleus was ovoid or oblong. Scale bar: 200 um. (c) SCs were marked with S-100ß by immunofluorescence. (d) The nucleus of SCs was marked with DAPI by immunofluorescence. (e) SCs and nucleus of SCs were merged together by immunofluorescence. Both of the two kinds of SCs had positive results under fluorescence microscope. Scale bar: $100 \mathrm{um}$. (f) The growth rate of SCs was showed by optical density (OD) value of $450 \mathrm{~nm}$ from 1 day to 7 days through cells proliferation assay. The growth rate of ASCs was obviously higher than that of NSCs starting from 2 days. 

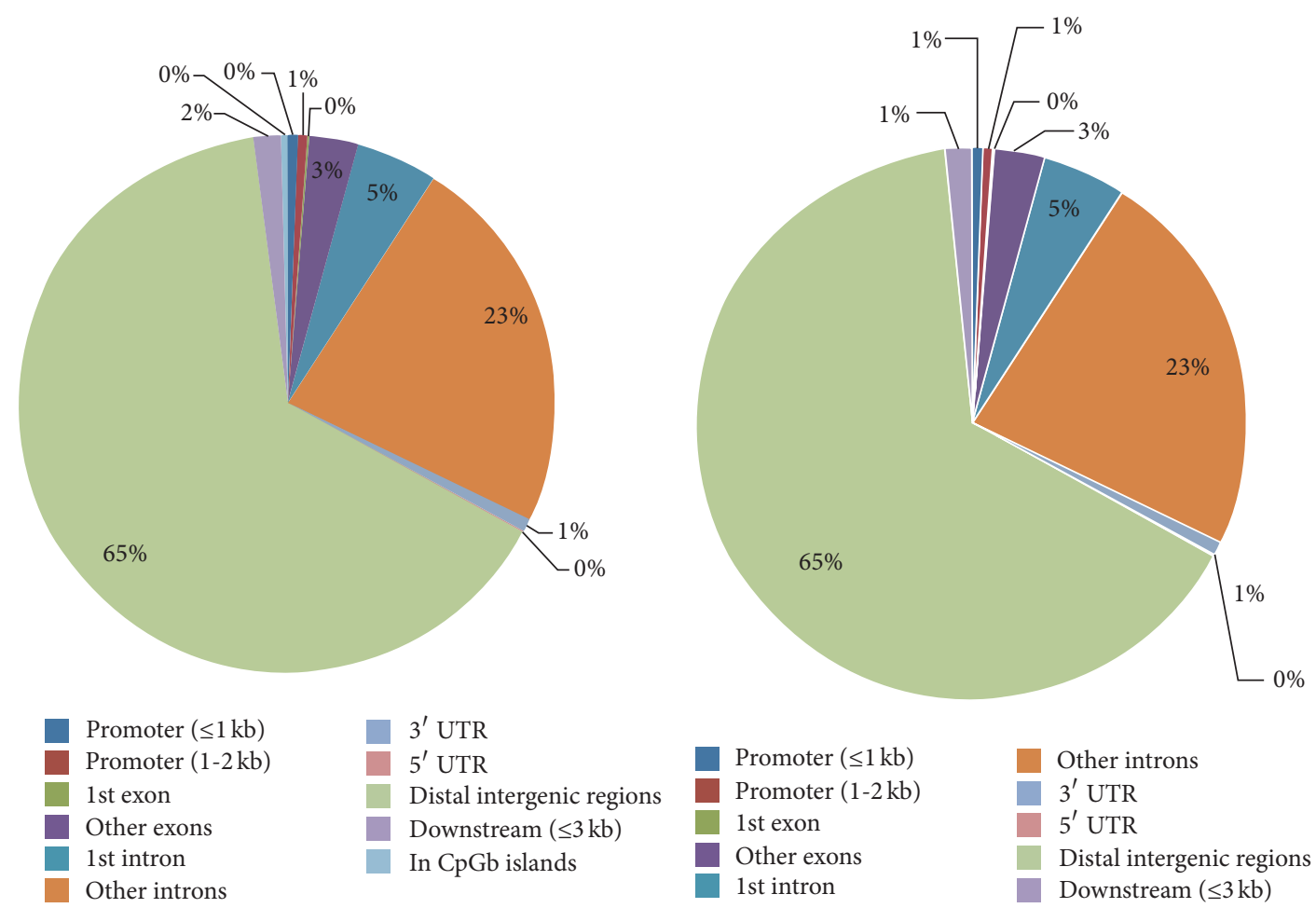

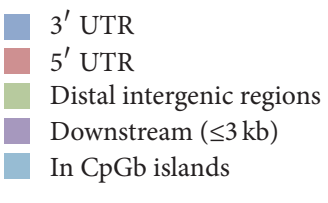

(a)

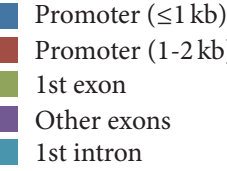

1 st intron

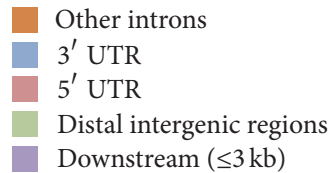

(b)

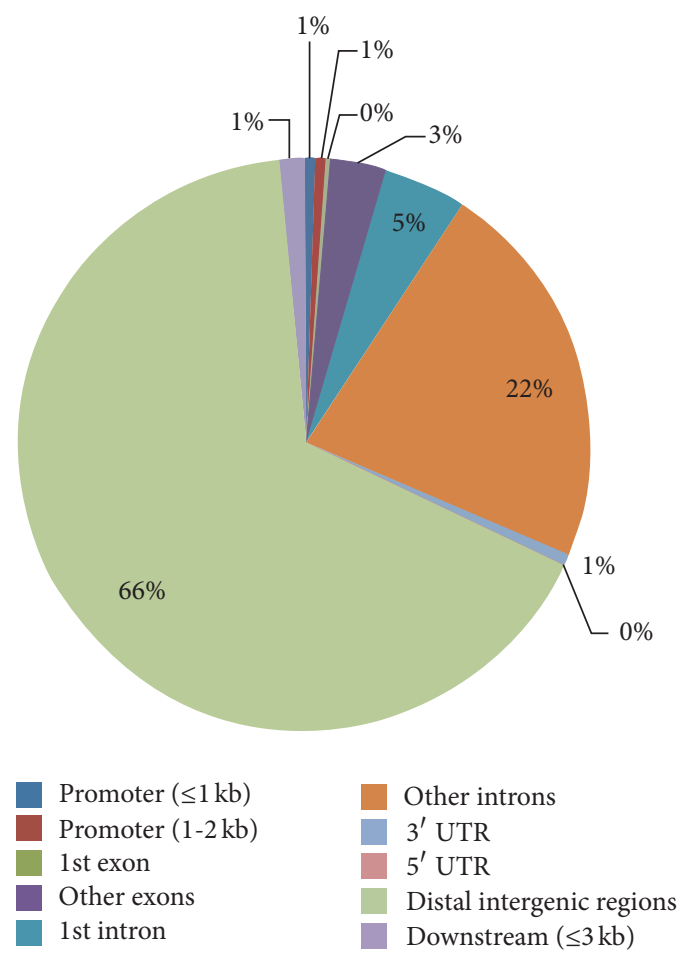

(c)

FIgURE 3: (a) The distribution of differentially methylated regions (DMRs) peaks in different components of genome. (b) The distribution of DMRs peaks in activated Schwann cells (ASCs). (c) The distribution of DMRs peaks in normal Schwann cells (NSCs). 
TABLE 1: Reads genome alignment statistics.

\begin{tabular}{|c|c|c|c|c|}
\hline \multirow{2}{*}{ Class } & \multicolumn{2}{|c|}{ ASCs } & \multicolumn{2}{|c|}{ NSCs } \\
\hline & Number & $\%$ & Number & $\%$ \\
\hline Total reads & 16816796 & & 17474976 & \\
\hline Total mapped ${ }^{\mathrm{a}}$ reads & 15729752 & 93.54 & 16415908 & 93.94 \\
\hline Total HQ mapped reads & 13005381 & 82.68 & 13137926 & 80.03 \\
\hline Promoter $(\leq 1 \mathrm{~kb})$ & 90241 & 0.69 & 84170 & 0.64 \\
\hline Promoter (1-2 kb) & 81955 & 0.63 & 79542 & 0.61 \\
\hline 1st exon & 20000 & 0.15 & 17909 & 0.14 \\
\hline Other exons & 458938 & 3.53 & 430799 & 3.28 \\
\hline 1st intron & 625989 & 4.82 & 610668 & 4.65 \\
\hline Other introns & 2953913 & 22.72 & 2887216 & 21.99 \\
\hline $3^{\prime} \mathrm{UTR}$ & 91283 & 0.70 & 87248 & 0.66 \\
\hline $5^{\prime}$ UTR & 9569 & 0.07 & 9244 & 0.07 \\
\hline Distal intergenic regions & 8463689 & 65.10 & 8722453 & 66.43 \\
\hline Downstream $(\leq 3 \mathrm{~kb})$ & 204583 & 1.57 & 200206 & 1.52 \\
\hline In $\mathrm{CpG}^{\mathrm{b}}$ islands & 97569 & 0.62 & 79283 & 0.48 \\
\hline
\end{tabular}

${ }^{a}$ Reads were mapped by BWA database with the default parameter.

${ }^{\mathrm{b}} \mathrm{CpG}$ islands were downloaded from UCSC database.

ASCs: activated Schwann cells; NSCs: normal Schwann cells; HQ: high quality.

TABLE 2: Chromosome distribution of total HQ mapped reads.

\begin{tabular}{|c|c|c|c|c|}
\hline \multirow{2}{*}{ Class } & \multicolumn{2}{|c|}{ ASCs } & \multicolumn{2}{|c|}{ NSCs } \\
\hline & Number & $\%$ & Number & $\%$ \\
\hline Total HQ mapped reads & 13005381 & & 13137926 & \\
\hline chrl & 1454481 & 11.1836862 & 1543628 & 11.7494 \\
\hline chr2 & 1074744 & 8.26384094 & 1098163 & 8.35872 \\
\hline chr3 & 816906 & 6.28129234 & 808555 & 6.15436 \\
\hline $\operatorname{chr} 4$ & 814638 & 6.2638534 & 810404 & 6.16843 \\
\hline chr5 & 754336 & 5.80018379 & 755245 & 5.74859 \\
\hline chr6 & 662551 & 5.09443745 & 661399 & 5.03427 \\
\hline chr7 & 742593 & 5.70989039 & 748669 & 5.69853 \\
\hline chr8 & 633675 & 4.87240628 & 627670 & 4.77754 \\
\hline chr9 & 604079 & 4.64483893 & 601617 & 4.57924 \\
\hline chr10 & 615858 & 4.73540914 & 597108 & 4.54492 \\
\hline chr11 & 406076 & 3.12236912 & 403700 & 3.07278 \\
\hline chr12 & 386267 & 2.97005524 & 381848 & 2.90646 \\
\hline chr13 & 645303 & 4.96181542 & 707230 & 5.38312 \\
\hline chr14 & 588247 & 4.52310471 & 584761 & 4.45094 \\
\hline chr15 & 503096 & 3.86836802 & 509972 & 3.88168 \\
\hline chr16 & 431447 & 3.31744991 & 434373 & 3.30625 \\
\hline chr17 & 488717 & 3.7578061 & 480979 & 3.661 \\
\hline chr18 & 431679 & 3.31923378 & 428225 & 3.25946 \\
\hline chr19 & 363485 & 2.7948816 & 353620 & 2.6916 \\
\hline chr20 & 372963 & 2.86775912 & 361241 & 2.7496 \\
\hline $\operatorname{chrX}$ & 209019 & 1.60717322 & 231048 & 1.75863 \\
\hline chrM & 5221 & 0.04014492 & 8471 & 0.06448 \\
\hline
\end{tabular}

chr: chromosome; ASCs: activated Schwann cells; NSCs: normal Schwann cells; HQ: high quality. 
TABLE 3: Differential methylation of Schwann cells statistics.

\begin{tabular}{lcc}
\hline Class & Number & $\%$ \\
\hline Genome regions & 11610434 & 100 \\
DMR & 176610 & 1.52113177 \\
Hypermethylated & 77799 & 44.0512995 \\
Hypomethylated & 98811 & 55.9487005 \\
\hline
\end{tabular}

DMR: differentially methylated region.

methylated, only 567 methylated genes caught our attention. 433 hypermethylated genes were discovered such as Gpr4, Dgcr8, Zeb2, Dixdc1, Sox2, Shh, Lrfn3, Det1, Shox2, Abracl, Trdn, Irx2, Pabpc6, Sbk1, and Peg3. 134 hypomethylated genes which included Gpr126, Birc2, Sepw1, Irgq, Atp5sl, Hipk4, Ttc9b, Tulp2, Bex1, Mex3b, Ctsc, Gucy2d, Rrm1, Fam160a2, and Cdknlc were revealed.

3.5. GO and KEGG Analysis of Methylated Genes as Functional Categories. Hypermethylated and hypomethylated genes were significantly enriched $(p<0.05)$ in GOenrichment analysis of biological processes, molecular functions, and cellular components. Among biological process, methylated genes were mainly associated with biological regulation, cellular process, regulation of biological process, metabolic process, single-organism process, and others in Figure 4(a). Among molecular function, methylated genes were enriched into the category of binding activity, catalytic activity, molecular transducer activity, transporter activity, and others in Figure 4(b). In addition, methylated genes are predominantly involved in the cellular component including cell part, organelle, membrane, extracellular region, and others in Figure 4(c).

Signaling pathway analysis of hypermethylated and hypomethylated genes was conducted. A total of 279 signaling pathways were identified. Of them, 9 signaling pathways including cAMP signaling pathway, Wnt signaling pathway, ERK signaling pathway, PI3-Akt signaling pathway, Hippo/YAP signaling pathway, MAPK signaling pathway, Rap1 signaling pathway, cGMP-PKG signaling pathway, and calcium signaling pathway were considered to be significant $(p<0.05)$ in Table 5.

3.6. Genes Related to Repairment of Peripheral Nerve Injury. Differentially methylated genes related to repairment of peripheral nerve injury including adhesion, secretion, proliferation, neuronal regeneration, and axonal regeneration were uncovered. For adhesion, 580 methylated genes were identified, such as Sox-2, Shh, Lphn1, and Cdh9. 553 differentially methylated genes related to secretion including Lphn1, Pim3, and Plcd1 were found. We also confirmed 787 methylated genes associated with proliferation such as Dixdc1, Lrp6, Edn3, and Ephb1. For neuronal regeneration, 473 methylated genes were identified, like Bhlhb9, Cckar, Klhll, Dlg2, and others. In addition, 215 differentially methylated genes related to axonal regeneration including Ifrd1, Unc $5 c$, and Ntrk 2 were found. Detailed results have been summarized in Table 6 .
3.7. Genes Expression Validation by $q R T-P C R$. In addition to validating the MeDIP analysis results, qRT-PCR was used to quantify parts of mRNAs of corresponding methylated genes in ASCs compared with NSCs, such as 5 differentially hypermethylated genes (Dgcr8, Zeb2, Dixdc1, Sox2, and Shh) and 2 differentially hypomethylated genes (Gpr126, Birc2), resulting in the fact that they were closely related with repairment of peripheral nerve injury after searching PubMed. As shown in Figure 5, the mRNA expression patterns of Dgcr8, Zeb2, Dixdc1, Sox2, Shh, Gpr126, and Birc2 detected by qRTPCR were opposite with the corresponding gene methylation alteration of MeDIP analysis data with significance $(p<$ $0.05)$.

\section{Discussion}

Epigenetics is the branch of traditional genetics, whose meaning is that this action changes expression and function of genes and generates heritable phenotypes under the condition of unchanged DNA sequences [19]. DNA methylation is made up of DNA methyltransferase catalytic $S$ adenosine armour sulfur chlorate as a methyl donor, so cytosine can be converted to 5-methyl cytosine [20]. Gene methylation can change configurations of gene, thus affecting transcription of transcription factor and gene expression. As an epigenetic silencing mechanism, DNA methylation plays essential roles in several developmental and cellular processes such as transcription, $\mathrm{X}$-chromosome inactivation, and genomic imprinting [21, 22]. In this study, using high-throughput MeDIP-Seq, our data showed the different patterns of DNA methylation between ASCs and NSCs and provided a comprehensive, detailed picture of DNA methylation patterns and methylated gene expression levels in SCs, which helps to understand the DNA methylation mechanisms of SCs in repairing injured $\mathrm{PNS}$.

ASCs serve a critical role in nerve remyelination after PNS injury, which are specialised glial cells and myelin-forming cells in PNS [23]. PNS injury leads to Wallerian degeneration in the distal stump and ASCs proliferate to form bands of Bungner as cellular scaffold, providing the essential guidance and support for regenerating axons [24, 25]. In addition, when PNS was injured, NSCs changed into ASCs to work. Our data proved once again that ASCs had better division rate and growth rate, which indicated that ASCs were more effective for structural and functional recovery of PNS injury.

DNA methylation peak number shows the popularity of methylation in genome. More DNA methylation peaks mean more loci in genome are methylated. Our data indicated that the distribution of DMRs peaks in different components of genome showed that uniquely mapped reads in distal intergenic regions had a relatively higher methylation level but only 567 DMRs peaks in CGls account for only 0.32 percent. It should also be noted that DNA methylation does not occur exclusively at CGls. In fact, recently tissue-specific DNA methylation has been found at $\mathrm{CpG}$ island shores, outlying areas close to CGls (up to $2 \mathrm{~kb}$ distance), and strongly related to gene expression inactivation $[26,27]$. To sum up, the 567 DMRs peaks in CGls of our findings are considered 
TABLE 4: Calculating CpG enrichment of provided short reads compared to the reference genome.

\begin{tabular}{|c|c|c|c|c|c|}
\hline Class & CpGs number & $\begin{array}{c}\text { CpGs rel. } \\
\text { frequency (\%) }\end{array}$ & CpGs obs/exp & $\begin{array}{l}\text { Enrichment rel. } \\
\text { frequency }(\%)\end{array}$ & $\begin{array}{c}\text { Enrichment } \\
\text { obs/exp }\end{array}$ \\
\hline BSgenome.Rnorvegicus.UCSC & 24713205 & 0.851414595 & 0.247437644 & - & - \\
\hline ASCs_1 & 73092752 & 2.01814666 & 0.393297098 & 2.37034539 & 1.589479639 \\
\hline ASCs_2 & 66573452 & 1.986667228 & 0.38941539 & 2.333372296 & 1.57379202 \\
\hline ASCs_3 & 56781764 & 2.026584608 & 0.394905638 & 2.380255893 & 1.595980428 \\
\hline NSCs_1 & 68221902 & 1.916242372 & 0.381639103 & 2.25065718 & 1.542364761 \\
\hline NSCs_2 & 62275625 & 1.922886765 & 0.382886143 & 2.258461126 & 1.547404574 \\
\hline NSCs_3 & 67670669 & 1.982610575 & 0.391849804 & 2.328607692 & 1.583630515 \\
\hline
\end{tabular}

rel: relative; obs: observed; exp: expected; ASCs: activated Schwann cells; NSCs: normal Schwann cells.

All statistics of calculations and plot are using MEDIPS, R package for MeDIP-Seq. BSgenome, Rnorvegicus, and UCSC were all genome databases.

TABLE 5: Significant KEGG signaling pathways of methylated genes.

\begin{tabular}{lccc}
\hline Pathway & Gene number & $p$ value & Partial related methylated genes \\
\hline Calcium signaling pathway & 136 & 0.01 & Phka2, Adcy7, Hrh2, Drd1, Grm1, Vdac1, Grm5, Pdelb, Tnnc2, Nos1, Camk4 \\
cAMP signaling pathway & 143 & 0.02 & Vav3, Drd2, Adcy10, Rhoa, Sox9, Mc2r, Gli3, Cngb3, Rras, Adcyl, Rac1 \\
cGMP-PKG signaling pathway & 126 & 0.02 & Adcy7, Irs1, Npr2, Mylk, Rhoa, Adrb1, Ins2, Adcy5, Gna12, Itpr3, Prkg1 \\
Wnt signaling pathway & 105 & 0.03 & Fzd5, Nlk, Smad4, Chd8, Plcb1, Sfrp4, Sost, Mapk8, Gsk3b, Lrp5, Rac1 \\
Rap1 signaling pathway & 150 & 0.03 & Kit, Magil, Krit1, Plce1, Pgf, Csf1, Tln1, Cdh1, Skap1, Fgf8, Rac1, Actg1 \\
ERK signaling pathway & 62 & 0.04 & Mtor, Nck1, Erbb3, Egf, Araf, Pak7, Shc3, Plcg2, Ptk2, Tgfa, Nrg1, Kras \\
PI3-Akt signaling pathway & 209 & 0.04 & Itga4, Ccne1, Gng7, Cdc37, Tlr2, Ccnd3, Gngt1, Hgf, Syk, Fgf1, Tnr, Tnc \\
Hippo/YAP signaling pathway & 104 & 0.04 & Fzd5, Mpp5, Crb2, Gsk3b, Tead1, Ccnd1, Actb, Smad3, Dlg1, Fzd4, Bmp7 \\
MAPK signaling pathway & 172 & 0.04 & Atf2, Cd14, Rras2, Ntf3, Rap1b, Grb2, Dusp1, Stk4, Mapk3, Jun, Nf1 \\
\hline
\end{tabular}

KEGG: Kyoto Encyclopedia of Genes and Genomes.

to be meaningful in DNA methylation mechanisms of SCs in repairing injured $\mathrm{PNS}$.

In order to disclose the underlying molecular mechanisms of SCs in repairing injured PNS, we characterized the possible GO functional terms and signaling pathways of differentially methylated genes using the GO function and KEGG analysis. Considering the results of GO function analysis, we linked the differentially methylated genes with biological regulation, cellular process, regulation of biological process, metabolic process, single-organism process, and other biological processes which are probably very important for the injured PNS repair process of SCs. As previous articles reported, our KEGG pathway analysis showed that cAMP signaling pathway, Wnt signaling pathway, ERK signaling pathway, PI3-Akt signaling pathway, Hippo/YAP signaling pathway, MAPK signaling pathway, and others were among the most relevant pathways for injured PNS repair process of SCs. Calcitonin gene-related peptides could activate the cAMP-PKA-ERK signaling cascade, which may play a direct role in initiating inflammatory processes in the PNS [28, 29]. Tao et al. [30] discovered that carboxymethylated chitosan can promote the proliferation of cultured SCs and synthesis of nerve growth factor by activating the Wnt/b-catenin signaling pathway. Napoli et al. [31] identified a central role for ERK signaling in SCs in orchestrating nerve repair and it was a powerful system for studying peripheral neuropathies. By activating p38 MAPK and PI3K-Akt signal cascades, Netrin-1 could enhance SCs migration [32]. Chang et al. [33] deemed that Alpiniae Oxyphyllae Fructus could increase PAs and MMP2/9 and activate MAPK mediated signaling to induce SCs migration and nerve regeneration. Besides, Melfi et al. [34] highlighted a new discovery that Hippo/YAP signaling pathway participated in forming tight junction and cell-tocell adhesion in SCs during PNS repair process. All these signaling pathways may play important roles in molecular mechanism of PNS repair process of SCs.

Also of note is that there were numerous evidences for our differentially methylated genes, which have proven to play important roles during PNS injury repairment. Glenn and Talbot [35] found that Gpr126 was essential for SCs to initiate myelination and addressed the role of Gpr126 signaling in myelin maturation and maintenance. Dgcr8 is responsible for modulation of myelin formation and maintenance as well as suppression of an injury-related gene expression program in SCs [36]. Quintes et al. [37] proved that Zeb2 is essential for Schwann cell differentiation, myelination, and nerve repair. By upregulating CyclinD1 and downregulating p21, Dixdc1 could activate PI3K pathway to promote Schwann cell proliferation after sciatic nerve crush [38]. Wang et al. [39] deemed that Birc2 and Birc3 of SCs, which might be the most potential targets for antiapoptotic protection mediated by inflammatory cytokines, were mainly responsible for the inflammation-mediated antiapoptosis of peripheral nerves. Besides, c-Jun-modified SCs, which have the potential to 


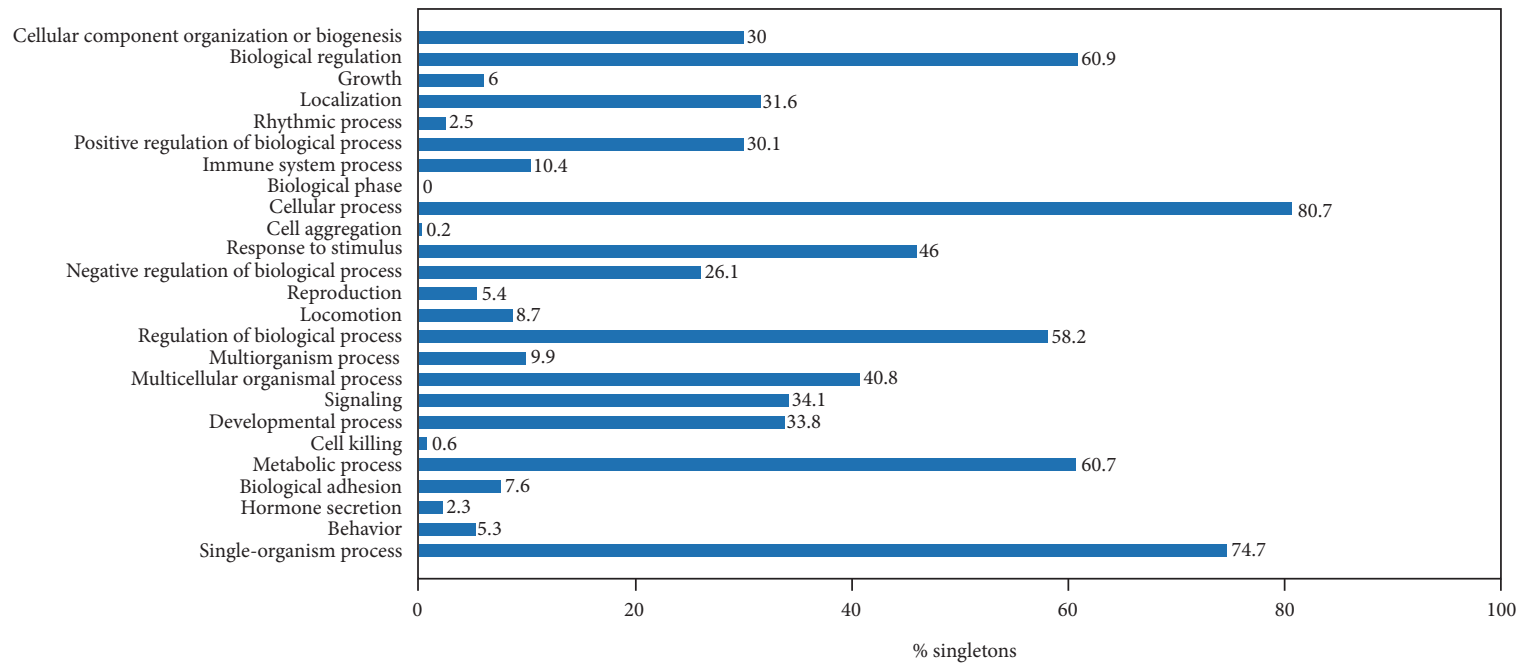

(a)

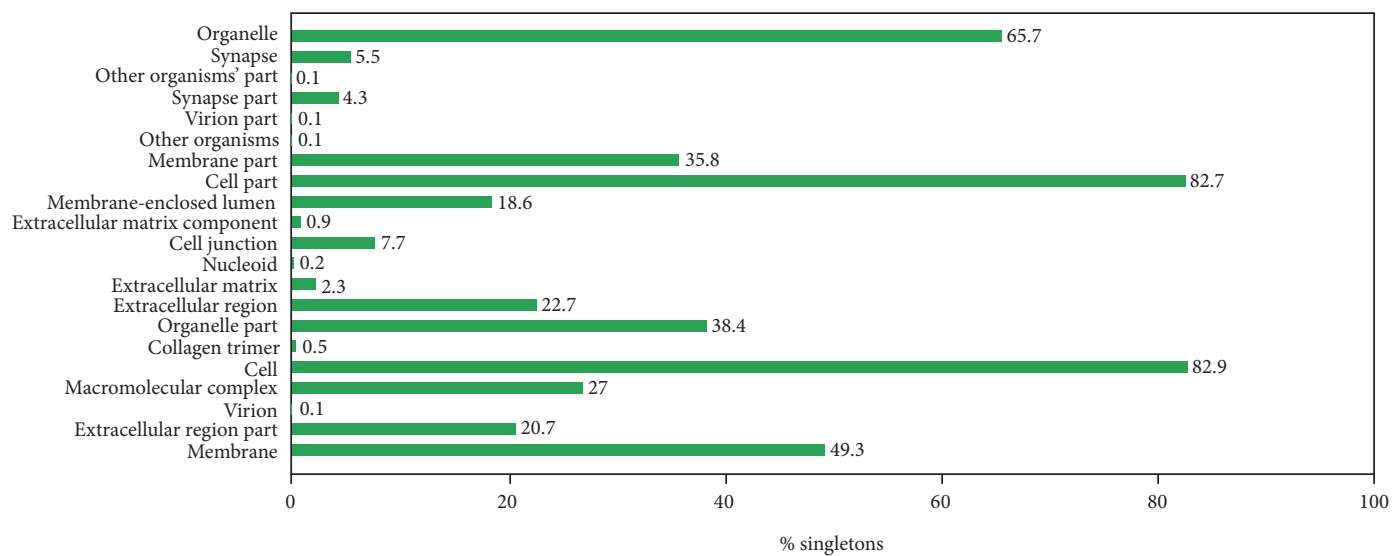

(b)

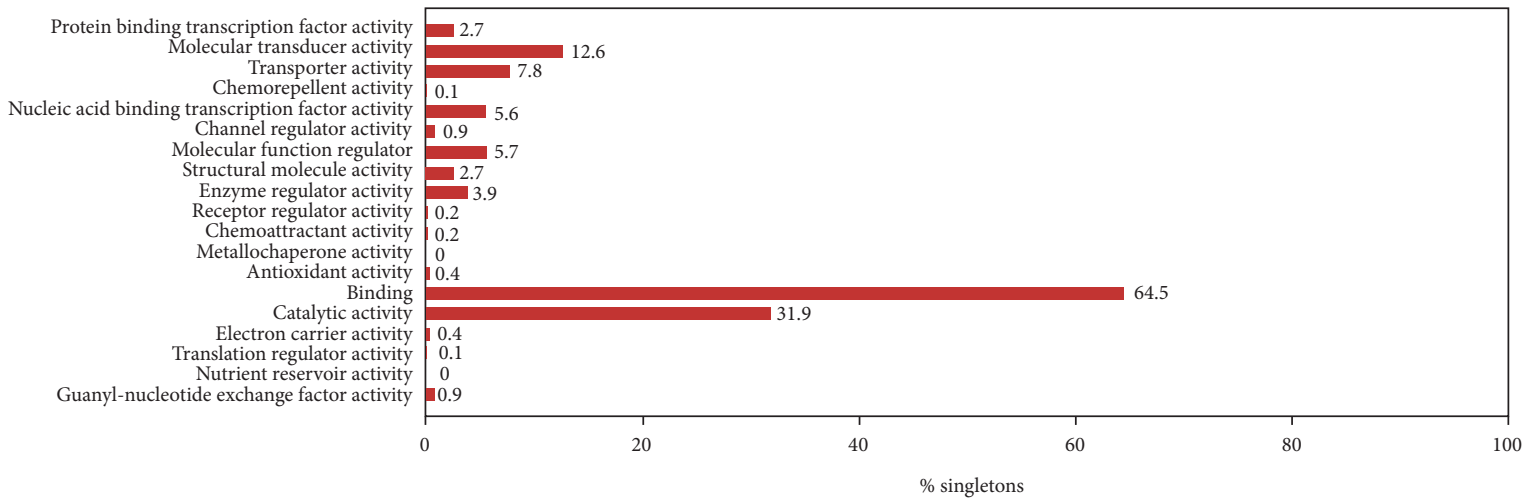

(c)

FigURE 4: GO-enrichment analysis of biological processes (a), cellular components (b), and molecular functions (c).

promote axonal regeneration and functional recovery, could enhance proliferation and migration abilities compared with control cells [40]. Sox2, as a negative regulator of myelination, could inhibit Schwann cell differentiation and myelination [41]. In addition, Shh gene, which is not normally expressed in SCs, is activated upon nerve injury. Lin et al. suggested that Sox-2 and Shh were involved in adhesion in SCs [36]. The mRNA expression patterns of Dgcr8, Zeb2, Dixdc1, Sox2, Shh, Gpr126, and Birc2 detected by qRT-PCR were opposite to the MeDIP analysis data with significance $(p<0.05)$. 
TABLE 6: Five aspects of genes related to repairment of peripheral nerve injury.

\begin{tabular}{|c|c|c|}
\hline Biological function & Gene number & Partial related methylated genes \\
\hline Adhesion & 580 & $\begin{array}{l}\text { Sox-2, Shh, Itpkb, Pkd1, Reln, Ptk2b, Nck2, Ass1 } \\
\text { Lphn1, Cdh9, Epdr1, Myf5, Pdpn, Has2, Fgfrl1, Fer }\end{array}$ \\
\hline Secretion & 553 & $\begin{array}{l}\text { Lphn1, Pim3, Fst, Pim3, Pcsk6, Lax1, Sct, Sytl3 } \\
\text { Plcd1, Ykt6, Jak1, Stat2, Myc, Csf2, Lifr, Sos1 }\end{array}$ \\
\hline Proliferation & 787 & $\begin{array}{l}\text { Dixdc1, Lrp6, Edn3, Nkx2, Cyr61, Src, Sox8, Stk4 } \\
\text { Ephb1, Sstr3, Rrm2, Tcf3, Grn, Rhoa, Apc, Nox4, Strn }\end{array}$ \\
\hline Neuronal regeneration & 473 & $\begin{array}{l}\text { Bhlhb9, Cckar, Fzd2, Thy1, Pbx3, Otx2, Lhx8, Btg2 } \\
\text { Klhl1, Dlg2, Pak1, Wnt3, Mif, Tctn1, Evl, Ext1, Als2 }\end{array}$ \\
\hline Axonal regeneration & 215 & $\begin{array}{l}\text { Ifrd1, c-Jun, Bcl2, Tnn, Mbp, Slit3, Ist1, Drgx, Thy1 } \\
\text { Unc5c, Ntrk2, Isl1, Ptk2, Dscam, Atl1, Dnm2, Cxcl12 }\end{array}$ \\
\hline
\end{tabular}

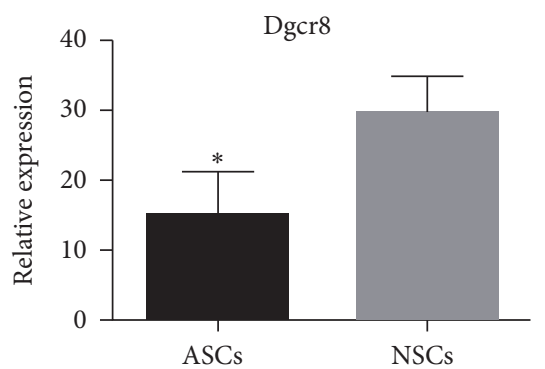

(a)

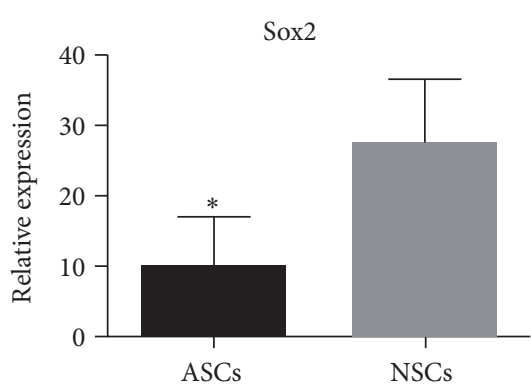

(d)

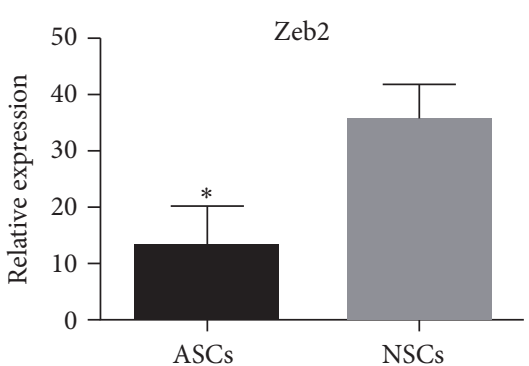

(b)

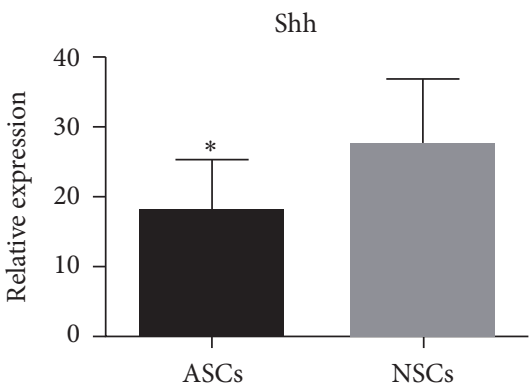

(e)

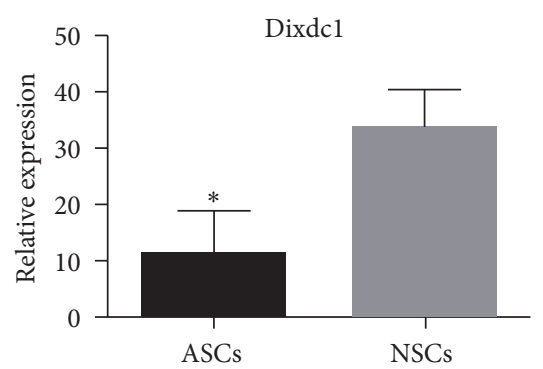

(c)

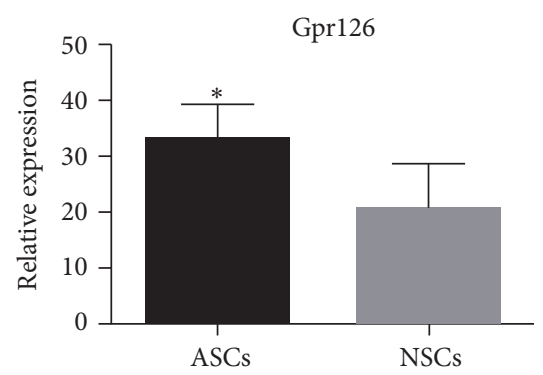

(f)

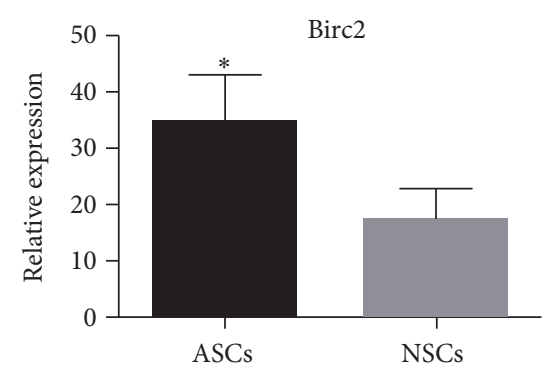

(g)

FIGURE 5: Validation of the differential expression of 7 mRNAs of corresponding methylated genes identified in the MeDIP in ASCs compared with NSCs by qRT-PCR. Data indicate relative expression following normalization. Values are means \pm SE $\left({ }^{*} p<0.05\right)$. (a)-(e) showed that 5 mRNAs of differentially hypermethylated genes (Dgcr8, Zeb2, Dixdc1, Sox2, and Shh) were downregulated in ASCs compared with NSCs. (f)-(g) showed that 2 mRNAs of differentially hypomethylated genes (Gpr126, Birc2) were upregulated in ASCs compared with NSCs.

CGls of these genes are hypermethylated or hypomethylated, which would inhibit or promote the expression of their corresponding mRNAs. So our qRT-PCR results proved that MeDIP analysis data were real and believable. Last but not least, the differentially methylated genes merely by qRT-PCR are not enough. Further experiments should be carried out to verify the CPG methylation of these differential methylated genes by bisulfite sequencing PCR (BSP).

\section{Conflicts of Interest}

The authors declare that they have no conflicts of interest. 


\section{Authors' Contributions}

Xian-Hu Zhou, Wei Lin, and Yi-Ming Ren contributed equally to this work.

\section{Acknowledgments}

The authors are grateful for the support by the State Program of National Natural Science Foundation of China (81371957), the State Key Program of the National Natural Science Foundation of China (81330042), the Special Program for SinoRussian Joint Research Sponsored by the Ministry of Science and Technology, China (2014DFR31210), the International Cooperation Program of National Natural Science Foundation of China (81620108018), and the Key Program Sponsored by the Tianjin Science and Technology Committee, China (13RCGFSY19000, 14ZCZDSY00044).

\section{References}

[1] K.-A. Nave and B. D. Trapp, "Axon-glial signaling and the glial support of axon function," Annual Review of Neuroscience, vol. 31, no. 1, pp. 535-561, 2008.

[2] D. K. Hartline and D. R. Colman, "Rapid conduction and the evolution of giant axons and myelinated fibers," Current Biology, vol. 17, no. 1, pp. R29-R35, 2007.

[3] B. Beirowski, E. Babetto, J. P. Golden et al., "Metabolic regulator LKB1 is crucial for Schwann cell-mediated axon maintenance," Nature Neuroscience, vol. 17, no. 10, pp. 1351-1361, 2014.

[4] M. Varela-Rey, M. Iruarrizaga-Lejarreta, J. J. Lozano et al., "S-adenosylmethionine levels regulate the schwann cell DNA methylome," Neuron, vol. 81, no. 5, pp. 1024-1039, 2014.

[5] M. Coleman, "Axon degeneration mechanisms: commonality amid diversity," Nature Reviews Neuroscience, vol. 6, no. 11, pp. 889-898, 2005.

[6] K. R. Jessen and R. Mirsky, "The origin and development of glial cells in peripheral nerves," Nature Reviews Neuroscience, vol. 6, no. 9, pp. 671-682, 2005.

[7] X. Gu, F. Ding, Y. Yang, and J. Liu, "Construction of tissue engineered nerve grafts and their application in peripheral nerve regeneration," Progress in Neurobiology, vol. 93, no. 2, pp. 204-230, 2011.

[8] H. Jiang, W. Qu, Y. Li, W. Zhong, and W. Zhang, "Plateletderived growth factors-bb and fibroblast growth factors-base induced proliferation of schwann cells in a 3D environment," Neurochemical Research, vol. 38, no. 2, pp. 346-355, 2013.

[9] A. Heinen, N. Tzekova, N. Graffmann et al., "Histone methyltransferase enhancer of zeste homolog 2 regulates Schwann cell differentiation," Glia, vol. 60, no. 11, pp. 1696-1708, 2012.

[10] T. D. Glenn and W. S. Talbot, "Signals regulating myelination in peripheral nerves and the Schwann cell response to injury," Current Opinion in Neurobiology, vol. 23, no. 6, pp. 1041-1048, 2013.

[11] J. A. Pereira, R. Baumann, C. Norrmén et al., "Dicer in Schwann cells is required for myelination and axonal integrity," Journal of Neuroscience, vol. 30, no. 19, pp. 6763-6775, 2010.

[12] J. D. Verrier, S. Semple-Rowland, I. Madorsky, J. E. Papin, and L. Notterpek, "Reduction of dicer impairs Schwann cell differentiation and myelination," Journal of Neuroscience Research, vol. 88, no. 12, pp. 2558-2568, 2010.
[13] Y. Chen, H. Wang, S. O. Yoon et al., "HDAC-mediated deacetylation of NF- $\kappa \mathrm{B}$ is critical for Schwann cell myelination," Nature Neuroscience, vol. 14, no. 4, pp. 437-441, 2011.

[14] C. Jacob, C. N. Christen, J. A. Pereira et al., "HDAC1 and HDAC2 control the transcriptional program of myelination and the survival of Schwann cells," Nature Neuroscience, vol. 14, no. 4, pp. 429-436, 2011.

[15] N. Hu, P. H. Strobl-Mazzulla, M. Simoes-Costa, E. SánchezVásquez, and M. E. Bronner, "DNA methyltransferase 3B regulates duration of neural crest production via repression of Sox10," Proceedings of the National Academy of Sciences of the United States of America, vol. 111, no. 50, pp. 17911-17916, 2014.

[16] R. Lindner, R. Puttagunta, T. Nguyen, and S. Di Giovanni, "DNA methylation temporal profiling following peripheral versus central nervous system axotomy," Scientific Data, vol. 1, Article ID 140038, 2014.

[17] A. Woodhoo, M. B. D. Alonso, A. Droggiti et al., "Notch controls embryonic Schwann cell differentiation, postnatal myelination and adult plasticity," Nature Neuroscience, vol. 12, no. 7, pp. 839$847,2009$.

[18] T. K. Morrissey, N. Kleitman, and R. P. Bunge, "Isolation and functional characterization of Schwann cells derived from adult peripheral nerve," Journal of Neuroscience, vol. 11, no. 8, pp. 2433-2442, 1991.

[19] K. D. Robertson, "DNA methylation and human disease," Nature Reviews Genetics, vol. 6, no. 8, pp. 597-610, 2005.

[20] P. A. Jones, "Functions of DNA methylation: islands, start sites, gene bodies and beyond," Nature Reviews Genetics, vol. 13, no. 7, pp. 484-492, 2012.

[21] R. Jaenisch and A. Bird, "Epigenetic regulation of gene expression: how the genome integrates intrinsic and environmental signals," Nature Genetics, vol. 33, supplement, pp. 245-254, 2003.

[22] L. Gao, Y. Geng, B. Li, J. Chen, and J. Yang, "Genome-wide DNA methylation alterations of Alternanthera philoxeroides in natural and manipulated habitats: implications for epigenetic regulation of rapid responses to environmental fluctuation and phenotypic variation," Plant, Cell and Environment, vol. 33, no. 11, pp. 1820-1827, 2010.

[23] H. A. Hung, G. Sun, S. Keles, and J. Svaren, "Dynamic regulation of Schwann cell enhancers after peripheral nerve injury," Journal of Biological Chemistry, vol. 290, no. 11, pp. 6937-6950, 2015.

[24] V. T. Ribeiro-Resende, B. Koenig, S. Nichterwitz, S. Oberhoffner, and B. Schlosshauer, "Strategies for inducing the formation of bands of Büngner in peripheral nerve regeneration," Biomaterials, vol. 30, no. 29, pp. 5251-5259, 2009.

[25] L. Klimaschewski, B. Hausott, and D. N. Angelov, "The pros and cons of growth factors and cytokines in peripheral axon regeneration," International Review of Neurobiology, vol. 108, pp. 137-171, 2013.

[26] R. A. Irizarry, C. Ladd-Acosta, B. Wen et al., "The human colon cancer methylome shows similar hypo- and hypermethylation at conserved tissue-specific CpG island shores," Nature Genetics, vol. 41, no. 2, pp. 178-186, 2009.

[27] A. Doi, I.-H. Park, B. Wen et al., "Differential methylation of tissue-and cancer-specific $\mathrm{CpG}$ island shores distinguishes human induced pluripotent stem cells, embryonic stem cells and fibroblasts," Nature Genetics, vol. 41, no. 12, pp. 1350-1353, 2009. 
[28] L. Wang, D. Yuan, D. Zhang et al., "Ginsenoside re promotes nerve regeneration by facilitating the proliferation, differentiation and migration of schwann cells via the ERK- and JNKdependent pathway in rat model of sciatic nerve crush injury," Cellular and Molecular Neurobiology, vol. 35, no. 6, pp. 827-840, 2015.

[29] K. Permpoonputtana, J. E. Porter, and P. Govitrapong, "Calcitonin gene-related peptide mediates an inflammatory response in Schwann cells via cAMP-dependent ERK signaling cascade," Life Sciences, vol. 144, pp. 19-25, 2016.

[30] H.-Y. Tao, B. He, S.-Q. Liu et al., "Effect of carboxymethylated chitosan on the biosynthesis of NGF and activation of the Wnt/ $\beta$-catenin signaling pathway in the proliferation of Schwann cells," European Journal of Pharmacology, vol. 702, no. 1-3, pp. 85-92, 2013.

[31] I. Napoli, L. A. Noon, S. Ribeiro et al., "A central role for the ERK-Signaling pathway in controlling Schwann cell plasticity and peripheral nerve regeneration in vivo," Neuron, vol. 73, no. 4, pp. 729-742, 2012.

[32] J. Lv, X. Sun, J. Ma et al., "Netrin-1 induces the migration of Schwann cells via p38 MAPK and PI3K-Akt signaling pathway mediated by the UNC5B receptor," Biochemical and Biophysical Research Communications, vol. 464, no. 1, pp. 263-268, 2015.

[33] Y.-M. Chang, C.-X. Ye, T.-J. Ho et al., "Alpinia oxyphylla Miquel fruit extract activates MAPK-mediated signaling of PAs and MMP2/9 to induce Schwann cell migration and nerve regeneration," International Journal of Artificial Organs, vol. 37, no. 5, pp. 402-413, 2014.

[34] S. Melfi, A. Colciago, G. Giannotti et al., "Stressing out the Hippo/YAP signaling pathway: toward a new role in Schwann cells," Cell Death and Disease, vol. 6, no. 10, Article ID e1915, 2015.

[35] T. D. Glenn and W. S. Talbot, "Analysis of Gpr126 function defines distinct mechanisms controlling the initiation and maturation of myelin," Development, vol. 140, no. 15, pp. 31673175, 2013.

[36] H.-P. Lin, I. Oksuz, E. Hurley, L. Wrabetz, and R. Awatramani, "Microprocessor complex subunit DiGeorge syndrome critical region gene 8 (Dgcr8) is required for Schwann cell myelination and myelin maintenance," The Journal of Biological Chemistry, vol. 290, no. 40, pp. 24294-24307, 2015.

[37] S. Quintes, B. G. Brinkmann, M. Ebert et al., "Zeb2 is essential for Schwann cell differentiation, myelination and nerve repair," Nature Neuroscience, vol. 19, no. 8, pp. 1050-1059, 2016.

[38] W. Wu, Q. Liu, Y. Liu, Z. Yu, and Y. Wang, "Dixdcl targets CyclinD1 and p21 via PI3K pathway activation to promote Schwann cell proliferation after sciatic nerve crush," Biochemical and Biophysical Research Communications, vol. 478, no. 2, pp. 956-963, 2016.

[39] Y. Wang, X. Tang, B. Yu et al., "Gene network revealed involvements of Birc2, Birc3 and Tnfrsfla in anti-apoptosis of injured peripheral nerves," PLoS ONE, vol. 7, no. 9, Article ID e43436, 2012.

[40] L. Huang, X. Quan, Z. Liu et al., "C-Jun gene-modified schwann cells: upregulating multiple neurotrophic factors and promoting neurite outgrowth," Tissue Engineering Part A, vol. 21, no. 7-8, pp. 1409-1421, 2015.

[41] N. Le, R. Nagarajan, J. Y. T. Wang, T. Araki, R. E. Schmidt, and J. Milbrandt, "Analysis of congenital hypomyelinating Egr2Lo/Lo nerves identifies Sox2 as an inhibitor of Schwann cell differentiation and myelination," Proceedings of the National
Academy of Sciences of the United States of America, vol. 102, no. 7, pp. 2596-2601, 2005. 

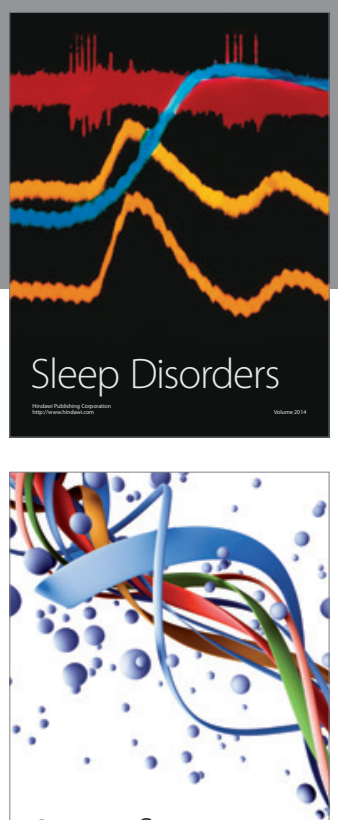

Scientifica
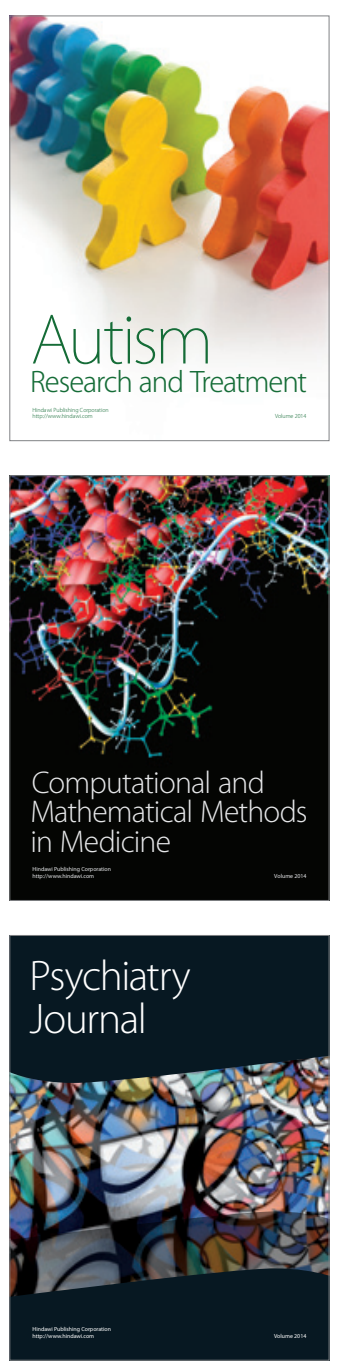
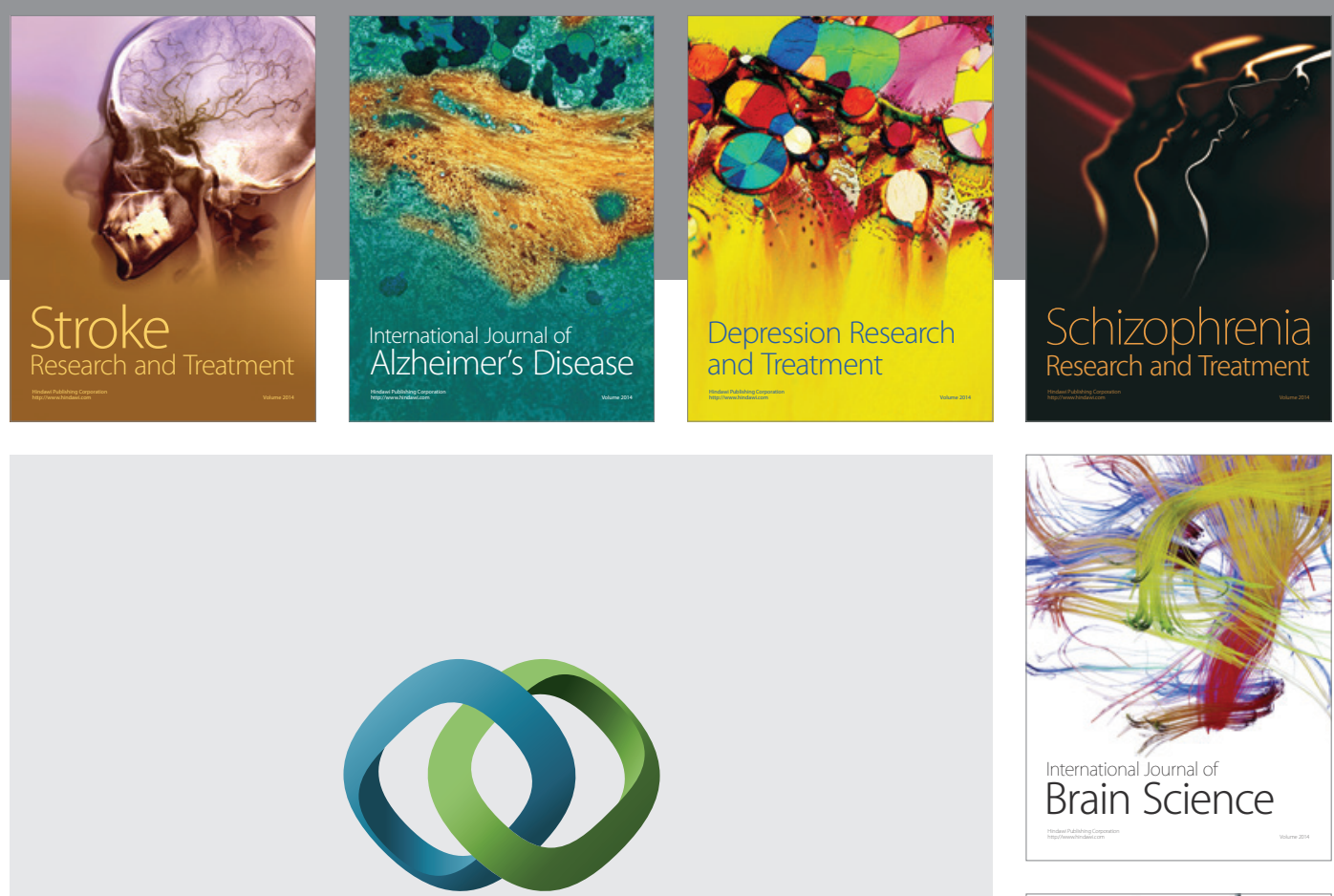

\section{Hindawi}

Submit your manuscripts at

https://www.hindawi.com
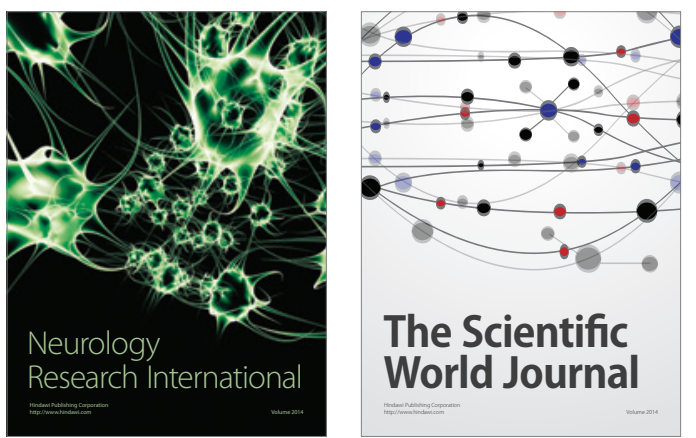

The Scientific World Journal

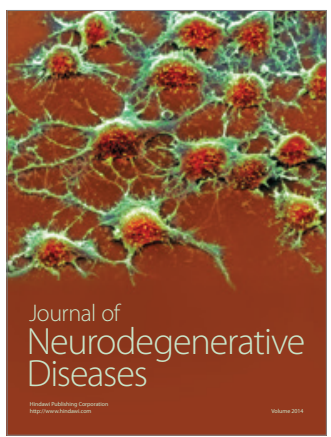

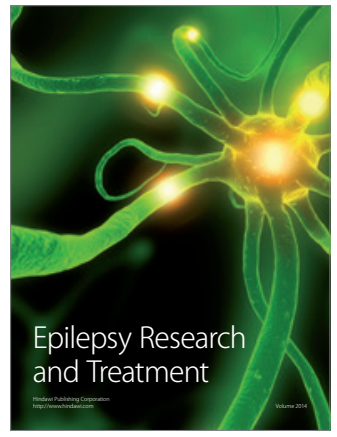

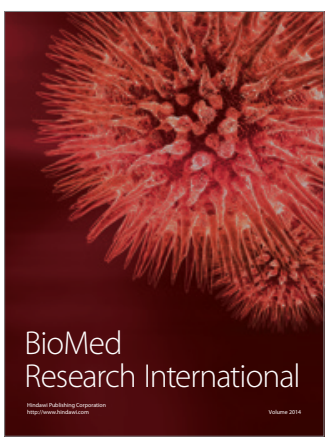

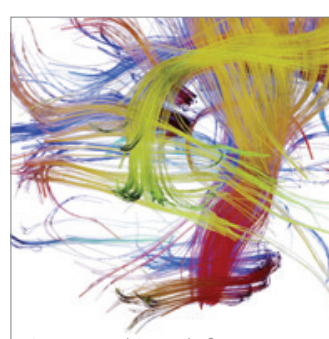

Brain Science

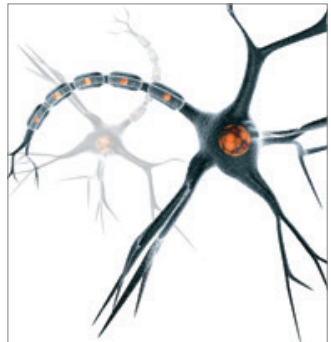

Neural Plasticity
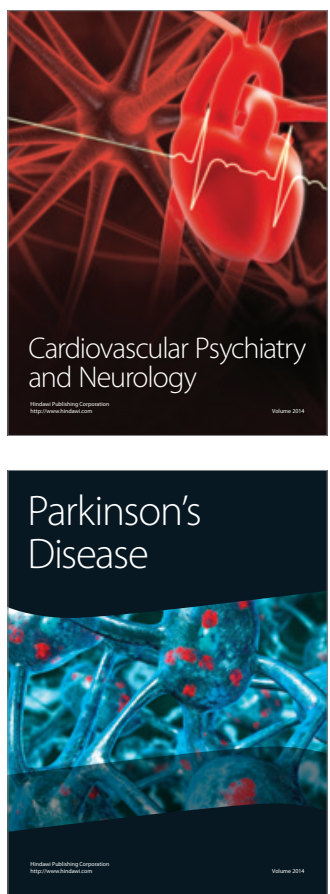